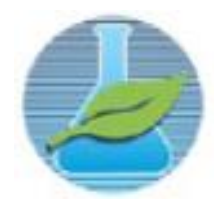

\author{
"EU, A INDÚSTRIA E O MUNDO" \\ 08 a 11 de novembro de 2016 no campus Viçosa da UFV \\ Departamento de Engenharia de Produção e Mecânica - DEP \\ Universidade Federal de Viçosa - UFV
}

\title{
OTIMIZAÇÃO ESTRUTURAL DE AERONAVE SAE BRASIL COM BASE EM ANÁLISE DE ELEMENTOS FINITOS
}

\author{
Guilherme Fernandes Guimarães \\ Universidade Federal de Viçosa, Departamento de Engenharia de Produção e Mecânica \\ Avenida Prof. Peter Henry Rolfs, s/n - Campus Universitário - 36570-000 - Viçosa - Minas Gerais \\ guilherme.f.guimaraes@ufv.br
}

\section{INTRODUÇÃO}

O Método dos Elementos Finitos (MEF) é uma análise de cunho matemático que consiste na discretização de um meio contínuo em pequenos elementos através da criação de uma malha poligonal. Os elementos da malha são descritos por equações diferenciais e processados por modelos matemáticos conhecidos, para que os resultados possam representar o comportamento aproximado. A origem do desenvolvimento deste recurso ocorreu no final do século XVIII, entretanto, a sua viabilização ocorreu somente com o desenvolvimento dos processadores, facilitando a resolução das enormes equações algébricas. A análise por elementos finitos se tornou especialmente importante no contex to industrial moderno, onde a competitividade da empresa está intimamente ligada à sua capacidade de otimizar produtos e processos. No contexto do aerodesign a simulação através de elementos finitos permite uma aproximação teórica do comportamento estrutural da aeronave, assim como o comportamento de um material ortrotópico como é o caso dos compósitos de fibra de carbono, que devido ao seu caráter não linear torna impossível a solução manual os esforços atuantes. Sendo assim, esse trabalho buscou otimizar a estrutura da aeronave projetada pela equipe Skywards Aerodesign usando a metodologia de elementos finitos.

\section{OBJETIVOS}

Através da análise por elementos finitos, o presente trabalho tem como objetivo otimizar a estrutura de uma aeronave para competição de Aerodesign considerando um material laminado de fibra de carbono com balsa. Os principais pontos a serem analisados são a distribuição de tensão e deslocamentos ao longo da estrutura e concentração de tensão.

\section{MATERIAIS E MÉTODOS}

Foram determinadas as propriedades mecânicas do material a ser estudado. Um dos ensaios feitos foi para determinar a resistência à tração do compósito de fibra de carbono. Como o laminado é fabricado manualmente, as propriedades dos corpos de prova devem apresentar um erro aleatório. Para minimizar o efeito desse erro no resultado de medição, foram utilizadas 10 amostras. O corpo de prova é composto por Resina Epóxi Araldite LY5052, endurecedor ARADUR 5052 CH, e fibra de carbono bidirecional ALLTEC. Conforme referido pela norma ASTM D3039M, a velocidade de ensaio foi de $2 \mathrm{~mm} / \mathrm{min}$, para que a ruptura dos corpos ocorresse entre 2 a $10 \mathrm{~min}$. Obtendo os seguintes resultados: 


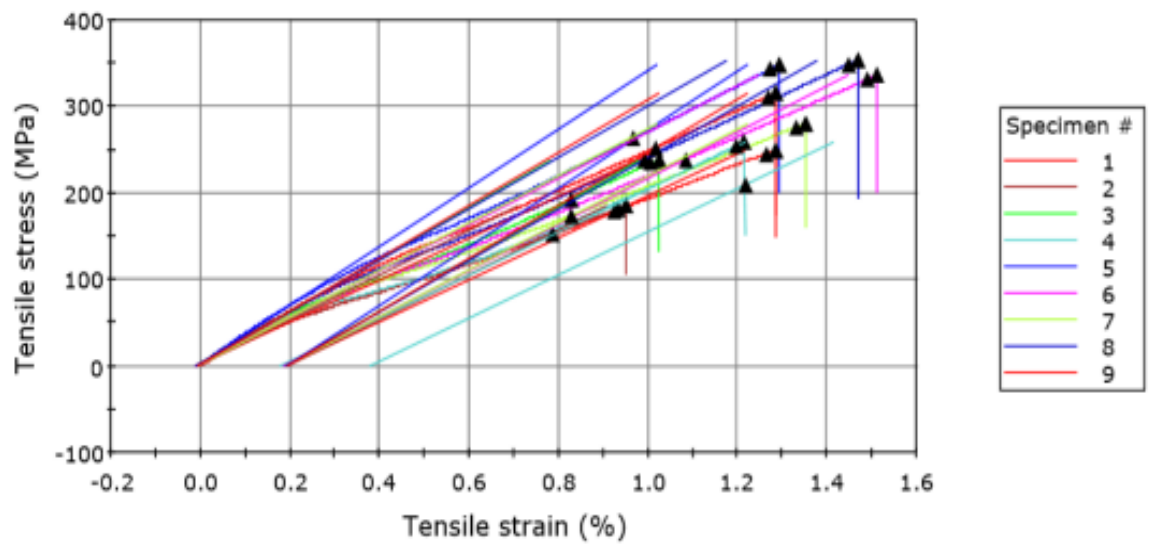

Figura 1- Resultados para Fibra 3 Camadas.

A partir do gráfico foi retirado uma tensão média de 284,7573 MPA com um coeficiente de variação de 30,1968 MPA, e desvio padrão de 50,86 MPA. Após obter as solicitações mecânicas, foram determinados esforços atuantes em voo e em solo. Para isso foram utilizadas simulações CFD para o perfil NACA em que foi determinada a sustentação gerada por esse. Além dos fatores de carga vide norma europeia (European Aviation Safety Agency - EASA) CS-VLA (Certification Specifications for Very Light Aeroplanes).

Com os esforços e propriedades dos materiais, um modelo-base foi projetado utilizando o software SolidWorks ${ }^{\circledR}$ e analisado pelo software ANSYS ${ }^{\circledR}$, segundo as condições explicitadas na Tab. 1. Através de uma primeira análise, foi projetado um segundo modelo para otimizar o primeiro. Após o teste do segundo, esse procedimento foi repetido a fim de obter o modelo mais próximo do ideal.

Tabela 1: Parâmetros de Análise.

\begin{tabular}{|c|c|c|c|}
\hline \multicolumn{5}{|c|}{ Parâmetros } \\
\hline Material & Boom 1 & Boom 2 & Boom 3 \\
\hline $\begin{array}{c}\text { Momento Máximo } \\
\text { (N.mm) }\end{array}$ & $\begin{array}{c}\text { Laminado Balsa } \\
\text { Carbono }\end{array}$ & $\begin{array}{c}\text { Laminado Balsa com } \\
\text { Fibra de Carbono }\end{array}$ & $\begin{array}{c}\text { Laminado Balsa com } \\
\text { Fibra de Carbono }\end{array}$ \\
\hline Nós da Malha & 186236 & 875 & 875 \\
\hline Elementos & 119934 & 157256 & 311270 \\
\hline Relevance Center & Fine & 106329 & Fine \\
\hline Smoothing & High & High & High \\
\hline Transition & Slow & Slow & Fine \\
\hline Span Angle Center & Fine & Fine & 0,326210 \\
\hline $\begin{array}{c}\text { Minimum Edge Length } \\
\text { (mm) }\end{array}$ & 0,011908 & 3,76290 & $-0,60981$ \\
\hline $\begin{array}{c}\text { Deformação Mínima } \\
\text { (mm) }\end{array}$ & $-2,2184$ & $-0,32051$ & 0,60979 \\
\hline $\begin{array}{c}\text { Deformação Maxima } \\
\text { (mm) }\end{array}$ & 2,6945 & 0,3422 & 0,00088007 \\
\hline Tensão Minima (MPa) & 0,00011747 & 0,0013366 & 34,998 \\
\hline Tensão Maxima (MPa) & 97,535 & 50,042 & \\
\hline
\end{tabular}

\section{RESULTADOS}


Após a primeira análise foi observado que mesmo atendeu a resistência de escoamento do laminado, no entanto a estrutura apresentava uma deflexão muito maior do que esperado. Com base do resultado apresentado pelo software foi possível observar que essa deflexão acontecia devido ao efeito de flambagem na estrutura. Com isso a estrutura foi reprojetada para resolver o problema. O segundo modelo a ser analisado estava dentro dos critérios mecânicos e de deflexão, no entanto apresentava pontos de grande concentração de tensão, o que com esforço cíclico poderia gerar uma falha. O modelo foi redesenhado pela terceira vez e analisado. Por fim obteve-se uma estrutura que distribuísse homogeneamente os esforços, atendendo os requisitos de carregamento e deflexão, como mostrado na Fig. 2.

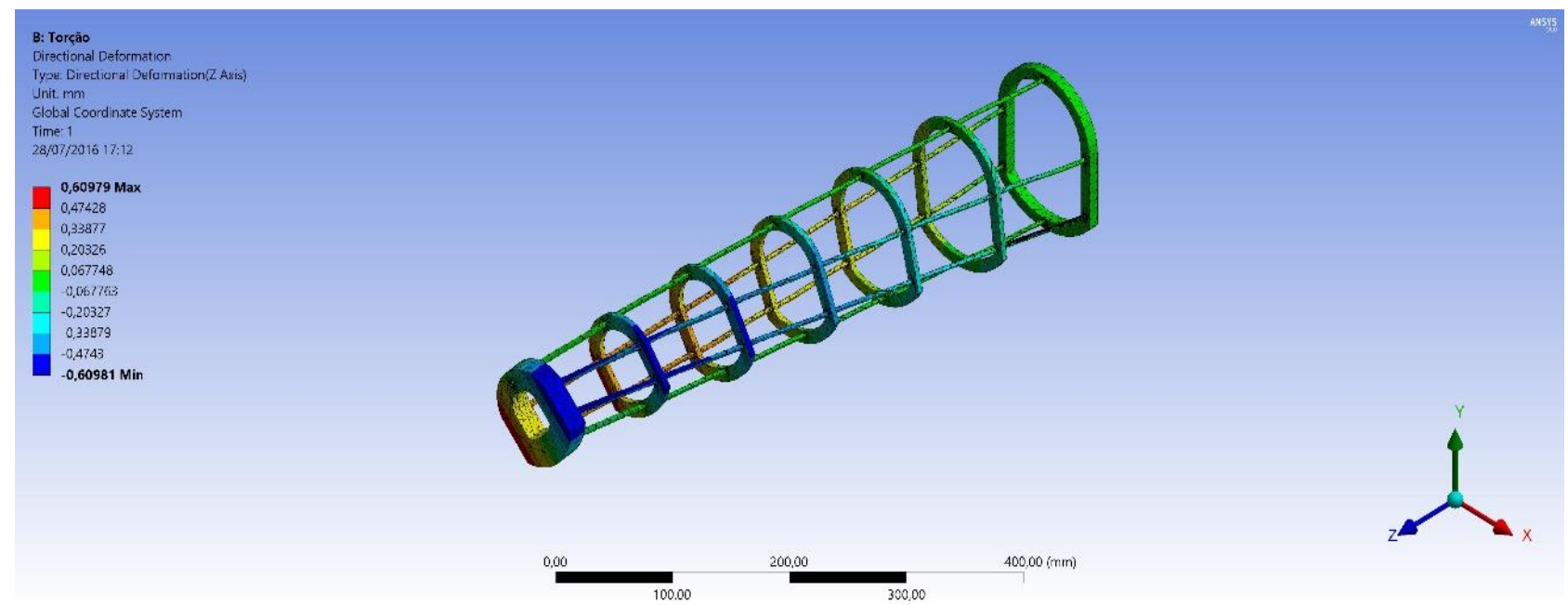

Figura 2 - Análise Final da Estrutura.

\section{CONCLUSÕES}

Verificou-se que ao utilizar o método de elementos finitos para explicitar as regiões de maior solicitação é possível otimizar a estrutura em projeto a fim de distribuir uniformemente as solicitações. Ao mesmo tempo que em outras regiões foi feito um alívio de peso, aumentando assim o coeficiente de eficiência estrutural do componente e a competitividade da aeronave, uma vez que essa apresentará uma estrutura leve, e ao mesmo tempo será capaz de resistir aos esforços solicitantes. Após esse estudo um protótipo de aeronave foi construído e validado em voo, levando a carga prevista sem sofrer nenhum tipo de dano.

\section{REFERÊNCIAS}

NIU, M. C-Y. “Airframe Stress Analysis and Sizing”. Second Edition, Hong Kong Conmilit Press LTD, 1999.

NIU, M. C-Y. “Airframe Structural Design”. Second Printing, Conmilit Press LTD, 1989.

FELIX, P. H. W. "Caracterização Mecânica de Materiais Compostos”. Relatório de Iniciação Científica, Universidade Federal de Viçosa, 2013.

FAR - Part 23 "Airworthiness standards: normal, utility, acrobatic and commuter".

RAYMER, D. P. “Aircraft Design: A Conceptual Approach”. Third Edition AIAA - American Institute of Aeronautics and Astronautics, 1999.

PAZMANY, L. “Light Airplane Design”. San Diego, California, 3ª ed., 1963. 